BMJ Open Sport \& Exercise Medicine

\title{
Femoroacetabular translation in female athletes and dancers assessed by dynamic hip ultrasonography
}

Charles P Scott (D) ,, ${ }^{1,2}$ Pierre A d'Hemecourt, ${ }^{1,2,3,4}$ Patricia E Miller, ${ }^{2,3}$

Dai Sugimoto, ${ }^{4,5}$ Sarah S Jackson, ${ }^{1,2,3,4}$ Greggory P Kobelski, ${ }^{4}$ Kristin E Whitney, ${ }^{1,2,3,4}$ Andrea Stracciolini (D) $1,2,3,4,6$

\section{ABSTRACT}

d'Hemecourt PA, Miller PE, et al. Femoroacetabular translation in female athletes and dancers assessed by dynamic hip ultrasonography. BMJ Open Sport \& Exercise Medicine 2021;7:e001169. doi:10.1136/ bmjsem-2021-001169

Accepted 17 November 2021

Check for updates

(c) Author(s) (or their employer(s)) 2021. Re-use permitted under CC BY-NC. No commercial re-use. See rights and permissions. Published by BMJ.

${ }^{1}$ Division of Sports Medicine, Department of Orthopedic Surgery, Boston Children's Hospital, Boston, Massachusetts, USA

${ }^{2}$ Harvard Medical School, Boston, Massachusetts, USA ${ }^{3}$ Department of Orthopedic Surgery, Boston Children's Hospital, Boston, Massachusetts, USA

${ }^{4}$ The Micheli Center for Sports Injury Prevention, Waltham, Massachusetts, USA

${ }^{5}$ Faculty of Sport Sciences, Waseda University, Tokyo, Japan ${ }^{6}$ Division of Emergency Medicine, Boston Children's Hospital, Boston, Massachusetts, USA

Correspondence to Dr Andrea Stracciolini; andrea.stracciolini@childrens. harvard.edu
Objective To compare femoroacetabular (FA) translation between dancers and athletes with hip pain and between dancers with and without hip pain.

Methods In this cross-sectional study, 171 female athletes and dancers with hip pain underwent dynamic hip ultrasound (DHUS) of FA translation in three positions: neutral (N), neutral with contralateral hip flexion (NF), apprehension position with contralateral hip flexion (EER-F). Multivariable linear regression analysis was used to assess variation in FA translation between dancers and athletes in the presence of age, Beighton score/ hypermobility, BMI, radiographic markers of acetabular dysplasia and femoral version angles. Symptomatic dancers were matched to asymptomatic dancer controls on age, height and BMI, and comparison analyses of FA translation were conducted controlling for matched propensity score and Beighton score.

Results In the symptomatic cohort, dancers were younger, had higher Beighton scores and were more hypermobile than non-dancers. Dancers also showed greater NF, EER-F and max US-min US (delta) compared with non-dancers (mean $5.4 \mathrm{~mm}$ vs $4.4 \mathrm{~mm}, \mathrm{p}=0.02$; mean $6.3 \mathrm{~mm}$ vs $5.2 \mathrm{~mm}, \mathrm{p}=0.01 ; 4.2 \mathrm{~mm}$ vs $3.6 \mathrm{~mm}, \mathrm{p}=0.03$, respectively). Symptomatic dancers showed greater NF and EER-F compared with asymptomatic dancers (mean $5.5 \mathrm{~mm}$ vs $2.9 \mathrm{~mm}, \mathrm{p}<0.001$; mean $6.3 \mathrm{~mm}$ vs $4.2 \mathrm{~mm}$, $p<0.001$, respectively). Comparison of symptomatic dancers with and without hip dysplasia showed no difference in DHUS measurements.

Conclusion DHUS measurements of FA translation are greater in female dancers with hip pain relative to female non-dancer athletes with hip pain and asymptomatic female dancers.

\section{INTRODUCTION}

Hip injuries are common in dancers, accounting for up to $17.2 \%$ of all musculoskeletal injuries, with even higher rates among professional dancers $(27.7 \%) .{ }^{1}$ The anatomic aetiologies of hip pain in this cohort are not clearly defined, but include femoroacetabular impingement (FAI), chondrolabral pathology and compensatory soft tissue injury. ${ }^{2}{ }^{3}$ Hip microinstability, defined as supraphysiologic

\section{Key messages}

What is already known

- Hip injuries are common in dancers, the aetiologies of which include femoroacetabular impingement (FAl), chondrolabral injury and compensatory periarticular soft tissue injuries.

- In dance, where extreme hip range of motion is required, hip microinstability may confer a performance advantage but may also be associated with chondrolabral injury.

- Dynamic hip ultrasound (DHUS) has recently been shown as an effective method to evaluate for FA translation at the point of care.

What are the new findings

- DHUS measurements of FA translation are greater in female dancers with hip pain relative to female non-dancer athletes with hip pain and asymptomatic female dancers.

- This study is the first we are aware of to perform between-group investigational comparisons of FA translation assessed by DHUS.

- DHUS of FA translation may inform management of complex hip pain in dancers and athletes.

translation of the femoral head relative to the acetabulum sufficient to impair normal stability, has recently received attention as an important clinical entity causing pain and functional impairment. ${ }^{4-6}$ Previous studies have demonstrated FA subluxation at the extremes of range of motion (ROM) together with a high prevalence of chondrolabral lesions in the hips of dancers, suggesting microinstability may contribute to chondrolabral injury in this group. ${ }^{78}$

In dance, where extreme hip ROM is required to meet the aesthetic demands of the art form, hip microinstability may confer a performance advantage while also predisposing to pain and morbidity. ${ }^{9}$ Dance training may select for individuals with anatomic and soft tissue features that allow them to meet rigorous $\mathrm{ROM}$ requirements. Specifically, these anatomic features 
may include hip bony morphology, including acetabular dysplasia, which is highly prevalent among ballet dancers. ${ }^{11}$ Moreover, ballet 'turn-out' emphasises supraphysiologic hip external rotation with hip extension, a position that closely resembles the apprehension test for anterior instability. This position conceivably places repetitive stress on the anterior soft tissue-stabilising structures, resulting in anterior translation of the femoral head. This relationship has been recently demonstrated in a cadaveric study aimed at determining the role of capsular laxity in hip microinstability. ${ }^{12}$

Validated, non-invasive methods to quantitatively assess hip microinstability are limited. Prior studies have shown that radiographs ${ }^{13}$ and MRI ${ }^{14}$ can detect femoral head translation at the extremes of hip ROM, but these imaging modalities are not always clinically practical or cost-effective. The evolving advancement of dynamic hip ultrasound (DHUS) and its integration into care of the dancer hip highlight the need for a diagnostic modality that offers an efficient, safe and cost-effective way to evaluate the hip in motion. This has become especially pertinent when caring for dancers with concern for hip microinstability, with or without radiographic evidence of acetabular dysplasia and FAI. DHUS has recently been shown to be an effective method to evaluate femoral head translation as it relates to the acetabulum in real time, and has the added benefit of allowing for patient feedback around symptom reproduction. ${ }^{15}$

A primary aim of this study was to gain a better understanding of the biodynamics of the FA articulation assessed by DHUS as it pertains to hip pain in dancers. We asked whether FA translation differs between female dancers with hip pain compared with a population of female non-dancer athletes with hip pain and compared with asymptomatic dancer controls. Another aim of this study was to determine the association between acetabular morphology and FA translation in dancers measured by DHUS. Our hypothesis was that we would demonstrate greater FA translation in dancers compared with nondancer athletes, and in symptomatic dancers compared with asymptomatic dancers. We also hypothesised that there would be an association found between acetabular dysplasia and FA translation as measured by DHUS.

\section{METHODS}

The study protocol was approved by the Institutional Review Board prior to commencement. Cross-sectional data analysis was performed in an on-going prospective study. Data collection was carried out between February 2018 and February 2020 in an orthopaedic sports medicine and hip preservation clinic specialising in musculoskeletal ultrasound and affiliated with a paediatric academic medical centre. Study subjects were female dancers or athletes and had radiographs (anterior-posterior (AP) and false-profile lateral views) and three-dimensional imaging (either MRI or CT) of the hip within 3 years of presentation. If a subject had bilateral injury, then a random side was selected, so that each subject only provided one hip for analysis. Exclusion criteria included male sex, prior hip surgery and comorbidities that would
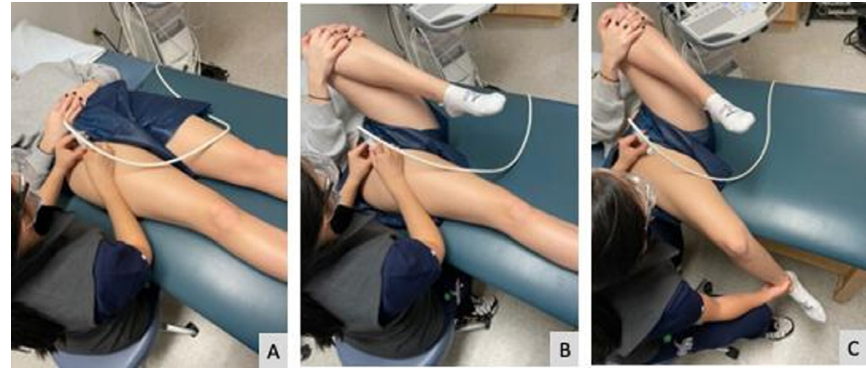

Figure 1 (A) The first position, neutral $(N)$, showing the subject supine with both hips in neutral position. (B) The second position, neutral with the contralateral hip flexed (NF), showing the subject with contralateral hip in flexion. (C) The third position, apprehension position with contralateral hip flexed (EER-F), with the ipsilateral hip in extension and external rotation with the contralateral hip flexed.

alter outcome measures, including arthritis, history of avascular necrosis or slipped capital femoral epiphysis.

Two hundred and eighty-one female subjects with hip pain were included. Sixteen subjects had incomplete imaging, 55 subjects had previous surgery and another 39 subjects reported no dance or sport participation or the primary sport was unknown. One hundred and seventy-one hips were included in the final analysisfigure 1. Demographic and additional clinical information was collected, including age, height $(\mathrm{cm})$, weight $(\mathrm{kg})$, body mass index (BMI) $\left(\mathrm{kg} / \mathrm{m}^{2}\right)$, 9-point Beighton score (validated measure of generalised hypermobility $)^{1617}$ and femoral version angles ${ }^{18}{ }^{19}$ obtained from cross-sectional imaging.

Asymptomatic controls were comprised of female ballet student dancers from an elite local performing arts high school. Demographic information for controls, including age, height $(\mathrm{cm})$, weight $(\mathrm{kg})$, BMI $\left(\mathrm{kg} / \mathrm{m}^{2}\right)$ and Beighton score, was collected by the attending physician at the time of ultrasound examination.

\section{Patient and public involvement}

While patients and the public were not directly involved in the study design, the idea for this study arose from discussions with dancers, dance medicine providers and our hip preservation team around the need for clinical tools to assess hip instability and to better understand its role in complex hip pain.

\section{Ultrasound measurements}

Two different ultrasound machines were used to perform the study: the GE Logiq E, GE Logiq S7. Ultrasound measurements of symptomatic subjects were collected at clinical encounters between 2018 and 2020, while measurements of asymptomatic controls were performed over two dedicated testing days. Measurements were performed by four attending-level sports medicine physicians who perform DHUS examinations daily. The DHUS protocol used for this study has been tested for feasibility and reliability. ${ }^{15}$ Subjects were examined in three different ultrasound positions. The first position was designated as the neutral (N) 
position with the patient lying supine with both hips in extension (figure 1A). In the second position, neutral with the contralateral hip flexed (NF), the patient was placed supine with the lumbar spine positioned flush to the examination table to stabilise the lumbar spine and pelvis while the contralateral hip was held in maximal flexion (figure 1B). In the third position, apprehension position with contralateral hip flexion (EER-F), the patient was supine with the lumbar spine flush to the table. The ipsilateral leg was placed in extension and external rotation over the edge of the examination table and the contralateral hip was flexed (figure 1C). This apprehension position was chosen as it actively places stress on the anterior structures of the hip, thereby reproducing anterior femoral head translation. Whereas lumbopelvic neutrality is maintained in the $\mathrm{N}$ position, the NF and EER-F positions were designed to prevent variability in pelvic tilt by having patients actively position the lumbar spine flush to the table. We feel that the DHUS measurements in the NF and EER-F positions are the preferred measurements and were previously deemed most reliable for interrater reliability according to d'Hemecourt et al. ${ }^{15}$ The delta calculation is the difference between maximum and minimum DHUS measurements. By quantifying the total arc of the translational moment, we feel that this calculation may represent the extent of FA translation. A high-frequency, linear ultrasound probe was used for each examination and was placed in the anatomic sagittal oblique plane over the anterior hip to visualise the femoral head and acetabulum. A point of maximal anterior femoral head translation was localised by scanning medial to lateral to identify the highest point of the femoral head in relation to the acetabulum (figure 2). To quantify translation, a measurement of femoral head position above the level of the acetabulum in millimetres was recorded using the internal software of each ultrasound machine. This measurement was considered positive when the femoral head

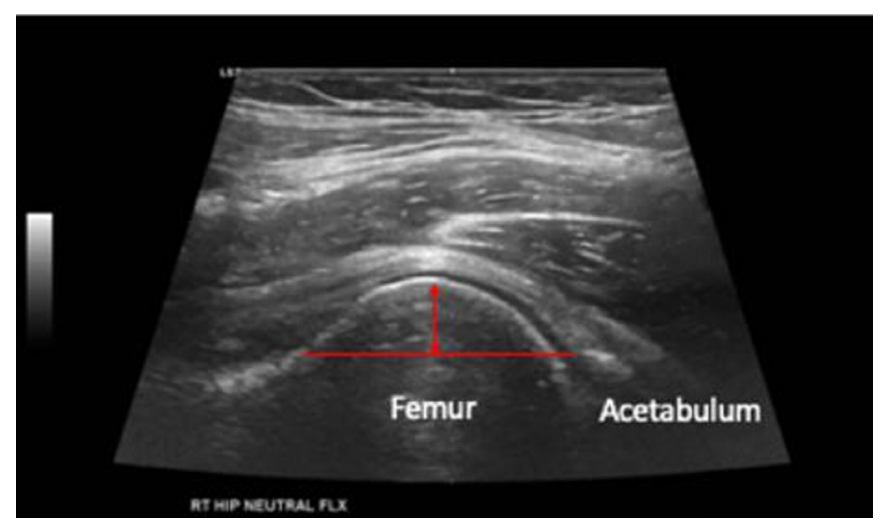

Figure 2 A point of maximal anterior femoral head translation was localised by scanning medial to lateral to identify the highest point of the femoral head in relation to the acetabulum. was above the level of the acetabulum and was negative when below the level of the acetabulum.

\section{Radiographic measurements}

The following angles were measured from the standing AP pelvic radiograph: lateral centre edge angle (LCEA) and Tönnis angle. ${ }^{20}$ The anterior centre edge angle (ACEA) was calculated from the lateral false profile radiograph. Acetabular dysplasia was defined radiologically when the LCEA was less than $25^{\circ}$ or, in the absence of LCEA, when the ACEA was less than $20^{\circ} .^{20}$ Sixty-two dancers and 109 non-dance athletes had AP and false profile radiographs available for measurement. Radiographs were reviewed and angles calculated by two different attending-level reviewers trained in sports medicine, musculoskeletal ultrasound and hip preservation. All three radiographic measurements have good inter-rater reliability. A recent systematic review examining reliability of common radiologic hip parameters found robust evidence for the reliability of the LCEA and Tönnis angles with more limited evidence in support of the reliability of the ACEA. ${ }^{21}$

\section{Statistical analysis}

Patient characteristics were summarised by mean and $\mathrm{SD}$, and categorical characteristics by frequency and percent, for all subjects and stratified across dancers and non-dancers. Bivariate comparisons in demographics, bony measurements and FA translation were conducted using Student's t tests and $\chi^{2}$ tests, as appropriate. Subgroup analysis was conducted within the cohort of symptomatic dancers between dysplastic and nondysplastic hips. Dysplasia was defined as a LCEA $<25^{\circ}$ or, if LCEA was missing and ACEA was available, if ACEA $<20^{\circ}$. Multivariable regression analysis was used to assess if there was any variation in the association between subgroups and FA translation in the presence of age, Beighton score/hypermobility, femoral version, LCEA and/or ACEA.

The symptomatic dancer cohort was matched to an asymptomatic dancer control group using propensity score matching. Symptomatic dancers were matched to asymptomatic dancers on age, height and BMI using an at most 1:2 ratio matching and a calliper of $0.1 \mathrm{SD}$ to narrow the nearest neighbour matching algorithm. The final match yielded 34 symptomatic and 53 asymptomatic dancers. Comparisons were conducted in DHUS measurements across symptomatic and asymptomatic dancers controlling for matched propensity score and Beighton score. $\mathrm{P}$ values less than 0.05 were considered significant.

\section{RESULTS}

Patient characteristics are summarised for all subjects $(\mathrm{N}=171)$ (table 1). The average age at US was 22.2 years (SD, 9.9; range, 12.0-63.8 years). The mean Beighton score was 4.9 (SD, 2.5), with $52 \%(89 / 171)$ of subjects exhibiting hypermobility (Beighton score $\geq 5$ ) (table 1). Performing arts (which included dance, cheerleading, gymnastics and figure 
Table 1 Cohort characteristics $(\mathrm{N}=171)$

\begin{tabular}{|c|c|c|c|c|}
\hline Characteristic & $\mathbf{N}$ & Mean & \pm SD & (Range) \\
\hline Age at US (vears; mean $\pm S D$ ) & 171 & 22.2 & \pm 9.86 & $(12-63.8)$ \\
\hline Height $(\mathrm{cm})$ & 168 & 165.2 & 7.3 & $(147.8-186)$ \\
\hline Weight $(\mathrm{kg})$ & 168 & 62.2 & 11.77 & $(33.4-101.8)$ \\
\hline BMI & 168 & 22.7 & 3.54 & $(15.3-35.7)$ \\
\hline Beighton score & 164 & 4.9 & \pm 2.45 & $(0-9)$ \\
\hline Hypermobility (frequency, \%) & 171 & 89 & $(52 \%)$ & \\
\hline Primary sport & $\mathbf{N}$ & Frequency & (\%) & \\
\hline Performing arts & 171 & 72 & $(42 \%)$ & \\
\hline Cutting & 171 & 33 & $(19 \%)$ & \\
\hline Recreational fitness & 171 & 20 & $(12 \%)$ & \\
\hline Squatting & 171 & 20 & $(12 \%)$ & \\
\hline Upright & 171 & 26 & $(15 \%)$ & \\
\hline
\end{tabular}

US, ultrasound.

skating) was the most common primary sport (42\%, 72/171) followed by cutting sports $(19 \%, 33 / 171)$. Our analysis compared dancers $(\mathrm{N}=62)$, comprising the large majority of our performing arts group, to non-dancers $(\mathrm{N}=109)$, a group comprised of all other performing artists and athletes in our total cohort.

\section{DHUS measurements in symptomatic dancers versus symptomatic non-dancers}

Bivariate comparisons between dancers and non-dancers determined that dancers were younger $(p=0.001)$, had higher Beighton scores $(\mathrm{p}=0.01)$ and were more likely to be hypermobile $(\mathrm{p}=0.02)$ (table 2$)$. Dancers had a greater mean NF measurement when compared with non-dancers (mean, 5.4mm vs $4.4 \mathrm{~mm}$; $\mathrm{p}=0.02$ ). Similarly, the mean EER-F measurement was greater in dancers when compared with non-dancers (mean $6.3 \mathrm{~mm}$ vs $5.2 \mathrm{~mm}$; $\mathrm{p}=0.01$ ). Finally, the delta was greater for dancers versus non-dancers $(4.2 \mathrm{~mm}$ vs $3.6 \mathrm{~mm}$; $\mathrm{p}=0.03$ ) (table 2 ).

\section{DHUS measurements in symptomatic dancers versus asymptomatic dancers}

Symptomatic and asymptomatic dancers were matched on age, height and BMI (table 3). No difference was detected in Beighton score $(\mathrm{p}=0.84)$ across groups or in the percent of hypermobile dancers $(p=0.57)$. In

Table 2 Patient and radiographic characteristics by dancer group $(\mathrm{N}=171)$

\begin{tabular}{|c|c|c|c|c|c|c|c|}
\hline & \multicolumn{3}{|c|}{ Dancers $(n=62)$} & \multicolumn{3}{|c|}{ Non-dancers $(n=109)$} & \multirow[b]{2}{*}{$P$ value } \\
\hline & Mean & \pm SD & (Range) & Mean & \pm SD & (Range) & \\
\hline \multicolumn{8}{|l|}{ Characteristic } \\
\hline Age at US & 19 & \pm 6.32 & $(12-40.4)$ & 24.2 & \pm 10.94 & $(12-63.8)$ & 0.001 \\
\hline Beighton score & 5.5 & \pm 2.32 & $(0-9)$ & 4.5 & \pm 2.44 & $(0-9)$ & 0.01 \\
\hline Hypermobility (frequency, \%) & 40 & $(65 \%)$ & & 49 & $(45 \%)$ & & 0.02 \\
\hline Height $(\mathrm{cm})$ & 163 & \pm 7.59 & $(147.8-183)$ & 166.2 & \pm 6.96 & $(149.3-186)$ & 0.02 \\
\hline Weight $(k g)$ & 60 & \pm 12.52 & $(33.4-100.3)$ & 63.7 & \pm 11.09 & $(44.1-101.8)$ & 0.03 \\
\hline $\mathrm{BMI}$ & 22 & \pm 3.71 & $(15.3-35.7)$ & 23 & \pm 3.42 & $(16.4-34.6)$ & 0.16 \\
\hline \multicolumn{8}{|l|}{ Radiographic } \\
\hline Version & 14 & \pm 8.86 & $(-9-37)$ & 17.6 & \pm 13.68 & $(-13-60)$ & 0.15 \\
\hline LCEA & 24 & \pm 6.10 & $(10-36)$ & 24.8 & \pm 7.09 & (3-49) & 0.73 \\
\hline ACEA & 23 & \pm 6.80 & $(7-38)$ & 23.3 & \pm 7.94 & $(7-50)$ & 0.93 \\
\hline Tönnis angle & 10 & \pm 4.81 & $(1-22)$ & 8.6 & \pm 5.73 & $(-5-29)$ & 0.07 \\
\hline \multicolumn{8}{|l|}{ Dynamic US } \\
\hline Neutral flexed & 5.4 & \pm 2.44 & $(0-14)$ & 4.4 & \pm 2.56 & $(-1.2-13.9)$ & 0.02 \\
\hline Neutral & 2.5 & \pm 2.72 & $(-1.2-14)$ & 2.1 & \pm 2.33 & $(-3.3-11.8)$ & 0.24 \\
\hline EER flexed & 6.3 & \pm 2.23 & $(2.8-12)$ & 5.2 & \pm 2.53 & $(0-14.3)$ & 0.01 \\
\hline Max US - Min US & 4.2 & \pm 1.63 & $(0.6-9)$ & 3.6 & \pm 1.73 & $(0-7.9)$ & 0.03 \\
\hline
\end{tabular}

ACEA, anterior centre edge angle; BMI, body mass index; EER, external rotation; LCEA, lateral centre edge angle; ; US, ultrasound. 
Table 3 Matched comparison between symptomatic and asymptomatic female dancer hips summary

\begin{tabular}{|c|c|c|c|c|c|}
\hline & \multicolumn{2}{|c|}{$\begin{array}{l}\text { Symptomatic } \\
(n=34)\end{array}$} & \multicolumn{3}{|c|}{$\begin{array}{l}\text { Asymptomatic } \\
(n=53)\end{array}$} \\
\hline & Mean & \pm SD & Mean & \pm SD & $P$ value \\
\hline \multicolumn{6}{|l|}{ Characteristics } \\
\hline Age & 16.1 & \pm 3.24 & 15.9 & \pm 1.14 & 0.80 \\
\hline Height & 164.4 & \pm 7.73 & 165.9 & \pm 5.53 & 0.36 \\
\hline Weight & 55.7 & \pm 9.36 & 55.4 & \pm 6.49 & 0.861 \\
\hline BMI & 20.5 & \pm 2.46 & 20.1 & \pm 2.26 & 0.50 \\
\hline Propensity score & 0.4 & \pm 0.21 & 0.4 & \pm 0.19 & 0.23 \\
\hline Beighton score & 5.5 & \pm 2.42 & 5.6 & \pm 2.10 & 0.84 \\
\hline $\begin{array}{l}\text { Hypermobility } \\
\text { (Beighton } \geq 5 \text { ) }\end{array}$ & 19 & $(56 \%)$ & 25 & $(47 \%)$ & 0.57 \\
\hline \multicolumn{6}{|l|}{ Dynamic US } \\
\hline Neutral flexed & 5.5 & \pm 2.00 & 2.9 & \pm 2.71 & $<0.001$ \\
\hline Neutral & 2.5 & \pm 2.50 & 1.4 & \pm 1.81 & 0.05 \\
\hline EER flexed & 6.3 & \pm 2.01 & 4.2 & \pm 3.11 & $<0.001$ \\
\hline Max US - Min US & 4.1 & \pm 1.53 & 3.3 & \pm 2.33 & 0.06 \\
\hline
\end{tabular}

BMI, body mass index; US, ultrasound.

general, US measurements were greater in symptomatic dancers compared with asymptomatic dancers. Specifically, the $\mathrm{N}$ measurements exhibited a difference of $0.9 \mathrm{~mm}$ on average, but this difference did not reach statistical significance $(2.5 \mathrm{~mm}$ vs $1.4 \mathrm{~mm}$; $\mathrm{p}=0.05$ ). For the NF measurements, dancers were found to have on average $2.6 \mathrm{~mm}$ greater translation when compared with asymptomatic dancers $(5.5 \mathrm{~mm}$ vs $2.9 \mathrm{~mm} ; \mathrm{p}<0.001$ ) (table 3 ). Similarly, the EER-F measurements for symptomatic dancers were on average of $2.1 \mathrm{~mm}$ greater compared with asymptomatic dancers $(6.3 \mathrm{~mm}$ vs $4.2 \mathrm{~mm} ; \mathrm{p}<0.001)$. A notable trend was detected in delta across dancer groups $(4.1 \mathrm{~mm}$ vs $3.3 \mathrm{~mm}$; $\mathrm{p}=0.06)$, but this did not reach statistical significance.

\section{DHUS measurements in symptomatic dancers with hip dysplasia versus without hip dysplasia}

Of the 62 symptomatic female dancers, 32 (52\%) of the dancers had dysplasia as determined by LCEA and ACEA measurements (table 4). No differences were detected in patient characteristics between subjects with dysplasia compared with those without dysplasia. With regards to DHUS measurements in dancers with and without dysplasia, no difference in DHUS measurements and delta was found (table 4).

\section{DISCUSSION \\ Main findings}

The main findings of our study were that female dancers with hip pain tended to be younger, more hypermobile and had greater hip FA translation on DHUS compared with non-dancer athletes with hip pain (table 2). DHUS FA translation was also greater in female dancers with hip pain relative to asymptomatic female dancers (table 3 ). These collective findings support the tendency towards hip microinstability in the dancer with hip pain.

Table 4 Patient and radiographic characteristics by dancers with and without dysplastic hips $(\mathrm{N}=62)$

\begin{tabular}{|c|c|c|c|c|c|c|c|}
\hline & \multicolumn{3}{|c|}{$\begin{array}{l}\text { Dysplastic* } \\
(\mathrm{n}=32)\end{array}$} & \multicolumn{3}{|c|}{$\begin{array}{l}\text { Not dysplastic } \\
(\mathrm{n}=30)\end{array}$} & \multirow[b]{2}{*}{$P$ value } \\
\hline & Mean & $\pm \mathrm{SD}$ & (Range) & Mean & $\pm \mathrm{SD}$ & (Range) & \\
\hline \multicolumn{8}{|l|}{ Characteristic } \\
\hline Age at US & 19.7 & \pm 7.26 & $(13-40.4)$ & 17.8 & \pm 5.07 & $(12-34.5)$ & 0.23 \\
\hline Beighton score & 5.8 & \pm 2.40 & $(0-9)$ & 5.3 & \pm 2.25 & $(1-9)$ & 0.48 \\
\hline Hypermobility (frequency) & 21 & $(66 \%)$ & & 19 & $(63 \%)$ & & 0.85 \\
\hline Height $(\mathrm{cm})$ & 163.8 & \pm 6.93 & $(150-182.6)$ & 162.9 & \pm 8.32 & $(147.8-183)$ & 0.63 \\
\hline Weight $(k g)$ & 60.3 & \pm 9.90 & $(44.1-84.9)$ & 58.9 & \pm 14.97 & $(33.4-100.3)$ & 0.65 \\
\hline BMI & 22.5 & \pm 3.35 & $(16.4-31.8)$ & 21.9 & \pm 4.10 & $(15.3-35.7)$ & 0.57 \\
\hline \multicolumn{8}{|l|}{ Radiographic measurement } \\
\hline Neutral flexed & 5.4 & \pm 2.94 & $(0-14)$ & 5.3 & \pm 1.81 & (2.2-9) & 0.85 \\
\hline Neutral & 2.8 & \pm 3.05 & $(-1.2-14)$ & 2.2 & \pm 2.32 & $(0-8.9)$ & 0.43 \\
\hline EER flexed & 6.7 & \pm 2.47 & $(2.8-12)$ & 5.8 & \pm 1.88 & $(3-9.7)$ & 0.16 \\
\hline Max US - Min US & 4.4 & \pm 1.65 & $(0.6-8.9)$ & 3.9 & \pm 1.60 & $(1.1-9)$ & 0.29 \\
\hline \multicolumn{8}{|l|}{ Radiographic measurement } \\
\hline Version & 13.8 & \pm 8.82 & $(-9-31)$ & 14.4 & \pm 9.12 & $(1-37)$ & 0.82 \\
\hline LCEA & 19.5 & \pm 3.77 & $(10-24)$ & 29.3 & \pm 3.39 & $(25-36)$ & - \\
\hline ACEA & 19.2 & \pm 6.02 & $(7-32)$ & 27.2 & \pm 4.97 & $(19-38)$ & - \\
\hline Tönnis & 13 & \pm 4.77 & $(1-22)$ & 7.4 & \pm 2.74 & $(2-12)$ & $<0.001$ \\
\hline
\end{tabular}

${ }^{*}$ Dysplasia was defined as a LCEA $<25^{\circ}$ or if LCEA was missing and ACEA was available, if ACEA $<20^{\circ}$.

ACEA, anterior centre edge angle; BMI, body mass index; EER, external rotation; LCEA, lateral centre edge angle; US, ultrasound. 
In our hip preservation clinics, we use DHUS measurements of FA translation daily as part of a comprehensive evaluation of the painful hip. The ability to quantitatively assess hip stability has several important clinical implications, including informing non-operative rehabilitation protocols and also surgical planning, where considerations around capsular management may have career-defining implications for dancers. ${ }^{22-24}$

Hip microinstability in dancers is likely multifactorial, with contributions from innate and/or acquired soft tissue laxity, supraphysiologic ROM demands and osseous morphology. ${ }^{6} 1325$ Hypermobility is well documented in dancers and has been proposed as a potential contributor to hip microinstability. ${ }^{39} 12172627$ In our study, DHUS FA translation and mean Beighton score were each greater in symptomatic dancers than in symptomatic non-dancers, with nearly two-thirds of symptomatic dancers meeting criteria for generalised hypermobility. Our findings lend support to the role of hypermobility as a potential contributor to microinstability in dancers with hip pain.

When comparing dancers with and without hip pain, although greater FA translation was observed in the symptomatic group, there was no observed difference in Beighton score across groups (table 3). This could suggest that acquired soft tissue laxity resulting from training demands, rather than innate generalised hypermobility, may be a more important contributor to hip microinstability, along with other anatomic factors.

Previously, the ability to assess FA translation was limited to static end-range radiographs and MRI involving dedicated imaging protocols typically reserved for research settings. DHUS can be advantageous over these traditional imaging modalities because it allows for evaluation of hip stability dynamically throughout the ROM. Additionally, DHUS is practical as it allows for point-of-care examination and image interpretation in real time and encourages patient feedback regarding symptom reproduction. This has the advantage of allowing for correlation of the patient's symptoms with translational moments occurring during dynamic motion. DHUS can be cost-effective and is practical for serial assessments over multiple patient encounters.

\section{Comparison with prior studies}

Many dancers have morphologic features consistent with FAI and/or dysplasia, ${ }^{11}$ and prior studies have demonstrated associations between FAI and increased hip instability among dancers. ${ }^{13} 1428$ Charbonnier applied motion capture and MRI data to three-dimensional models of hip joints in 11 dancers and found that FA impingement and hip joint instability are frequently observed at the end range of common ballet movements. ${ }^{14}$ Rodriguez used diagnostic ultrasound, rather than radiographs or threedimensional imaging, to identify hips with FAI morphology, which was then found to be clinically correlated with hip microinstability as assessed using physical examination manoeuvers. ${ }^{28}$ The DHUS protocol used in this study was previously shown to reliably assess anterior femoral head translation ${ }^{15}$; however, this is the first study to perform between-group investigational comparisons of FA translation assessed by DHUS.

Prior authors have proposed that acetabular dysplasia may contribute to hip microinstability in dancers, but objective demonstration of these associations in the literature is limited. Mitchell, for example, found strong associations between dysplasia and femoral head extrusion in male dancers using the splits radiograph, but this relationship was not significant in female dancers. ${ }^{13}$ We did not find acetabular dysplasia to be associated with greater FA translation among symptomatic dancers when controlling for ligamentous laxity and femoral sided bony morphology. These findings should be considered in the context of a relatively small and heterogenous dancer cohort $(n=62)$, and further studies will help to better clarify this relationship.

\section{Limitations}

Normative data are not yet available for this DHUS protocol, limiting our ability to contextualise the full clinical relevance of our findings. Thus, pain and functional outcome data may have provided additional clinical relevance to our study, but these were not available. DHUS and radiographic measurements were determined by clinicians who were unblinded to the subject's preferred sport and clinical status, a potential source of bias in data collection. Information about symptomatic dancers' primary dance style and level of expertise is lacking, in contrast with our control group, which was composed entirely of high school-level conservatory ballet dancers.

The ability to draw conclusions about the effects of acetabular coverage (dysplasia) on hip stability is limited by the unavailability of radiographic data for our control cohort. The ability to compare hip anatomy radiographically in dancers with and without hip symptoms is hindered by the challenge of obtaining imaging on healthy dancers. Nonetheless, these data are necessary to clarify the relationship between hip dysplasia and microinstability.

Future research is needed focusing on the range of FA translation in symptomatic and asymptomatic groups to establish normative data. Future studies will also evaluate DHUS to quantify posterior FA translation, which may be of particular significance for the dancer's hip.

\section{CONCLUSION}

Female dancers showed greater FA translation compared with non-dancer athletes, possibly related to ligamentous laxity and stretching of the anterior hip soft tissue stabilisers associated with dance training. Dancers with hip pain also showed greater FA translation relative to asymptomatic dancers. The clinical implication of our research is underscored by the notion that hip microinstability may be detrimental to hip articular cartilage. A better understanding of the relationships between hip morphology, soft tissue factors and hip microinstability is needed to develop appropriate prevention and treatment programmes for dancers and athletes with hip pain 
and occupational dysfunction. In this study, we employed a DHUS protocol that has previously been validated as a reliable means of evaluating FA translation. This study is the first we are aware of to perform between-group investigational comparisons of FA translation assessed by DHUS.

Contributors AS designed the study, collected the data, had full access to the data, interpreted the results, drafted the manuscript, provided critical reviews for the manuscript, and is responsible for the overall content as guarantor. CPS had full access to the data, interpreted results, and drafted the manuscript, and provided critical reviews for the manuscript. PAd'H, KEW and SSJ collected data for the study, had full access to the data, drafted the manuscript, and provided critical reviews for the manuscript. DS and GPK had full access to the data, interpreted the results, drafted the manuscript, and provided critical reviews for the manuscript. PEM performed summary analyses, drafted the manuscript and provided critical reviews for the manuscript. Each author reviewed and approved this manuscript prior to submission and during the revision process.

Funding The authors have not declared a specific grant for this research from any funding agency in the public, commercial or not-for-profit sectors.

Competing interests None declared.

Patient and public involvement Patients and/or the public were not involved in the design, or conduct, or reporting, or dissemination plans of this research.

Patient consent for publication Not applicable.

Ethics approval This study involves human participants and was approved by Boston Children's Hospital Institutional Review Board (IRB) 300 Longwood AvenueMailstop BCH 3164Boston, MA 02115Tel: (617) 355-7052Fax: (617) 7300226 www.bostonchildrens.org/research/irbProtocol Number: IRB-P00028871Date: $5 / 17 / 2018$ DHUS was the standard of care for the comprehensive clinical evaluation of complex hip pain in our Sports Medicine clinic. No informed consent was required.

Provenance and peer review Not commissioned; externally peer reviewed.

Data availability statement Data are available upon reasonable request. The data presented in this study are aggregated, de-identified participant data. The data presented were derived from Boston Children's Hospital, Department of Orthopedic Surgery, Division of Sports Medicine. Reuse of any data is available upon request and any reuse must give correct attribution to the author. Publishable contact details: Address correspondence to Andrea Stracciolini, MD, FAAP, FACSM, Boston Children's Hospital, Division of Sports Medicine, Department of Orthopedic Surgery, 300 Longwood Avenue, Boston, MA 02115.

Open access This is an open access article distributed in accordance with the Creative Commons Attribution Non Commercial (CC BY-NC 4.0) license, which permits others to distribute, remix, adapt, build upon this work non-commercially, and license their derivative works on different terms, provided the original work is properly cited, appropriate credit is given, any changes made indicated, and the use is non-commercial. See: http://creativecommons.org/licenses/by-nc/4.0/.

\section{ORCID iDs}

Charles P Scott http://orcid.org/0000-0002-0615-257X

Andrea Stracciolini http://orcid.org/0000-0003-2898-8527

\section{REFERENCES}

1 Trentacosta N, Sugimoto D, Micheli LJ. Hip and groin injuries in dancers: a systematic review. Sports Health 2017;9:422-7.

2 Turner R, O'Sullivan E, Edelstein J. Hip dysplasia and the performing arts: is there a correlation? Curr Rev Musculoskelet Med 2012:5:39-45.

3 Weber AE, Bedi A, Tibor LM, et al. The Hyperflexible hip: managing hip pain in the dancer and Gymnast. Sports Health 2015;7:10.1177/1941738114532431:346-58.
4 Bolia I, Chahla J, Locks R, et al. Microinstability of the hip: a previously unrecognized pathology. Muscle Ligaments and Tendons J 2016;06:354-60.

5 Dangin A, Tardy N, Wettstein M, et al. Microinstability of the hip: a review. Orthop Traumatol Surg Res 2016;102:S201-9.

6 Kalisvaart MM, Safran MR. Microinstability of the hip-it does exist: etiology, diagnosis and treatment. J Hip Preserv Surg 2015;2:123-35

7 Duthon VB, Charbonnier C, Kolo FC, et al. Correlation of clinical and magnetic resonance imaging findings in hips of elite female ballet dancers. Arthroscopy 2013;29:411-9.

8 Kolo FC, Charbonnier C, Pfirrmann CWA, et al. Extreme hip motion in professional ballet dancers: dynamic and morphological evaluation based on magnetic resonance imaging. Skeletal Radiol 2013;42:689-98.

9 Briggs J, McCormack M, Hakim AJ, et al. Injury and joint hypermobility syndrome in ballet dancers--a 5-year follow-up. Rheumatology 2009;48:1613-4.

10 Hamilton WG, Hamilton LH, Marshall P, et al. A profile of the musculoskeletal characteristics of elite professional ballet dancers. Am J Sports Med 1992;20:267-73.

11 Harris JD, Gerrie BJ, Varner KE, et al. Radiographic prevalence of dysplasia, $\mathrm{CaM}$, and pincer deformities in elite ballet. Am J Sports Med 2016;44:20-7.

12 Johannsen AM, Behn AW, Shibata K, et al. The role of anterior capsular laxity in hip Microinstability: a novel biomechanical model. Am J Sports Med 2019;47:1151-8.

13 Mitchell RJ, Gerrie BJ, McCulloch PC, et al. Radiographic evidence of hip microinstability in elite ballet. Arthroscopy 2016;32:1038-44.

14 Charbonnier C, Kolo FC, Duthon VB, et al. Assessment of congruence and impingement of the hip joint in professional ballet dancers. Am J Sports Med 2011;39:557-66.

15 d'Hemecourt PA, Sugimoto D, McKee-Proctor M, et al. Can dynamic ultrasonography of the hip reliably assess anterior femoral head translation? Clin Orthop Relat Res 2019;477:1086-98.

16 Beighton P, Paepe AD, Steinmann B, et al. Ehlers-danlos syndromes: revised nosology, Villefranche, 1997. Am J Med Genet 1998;77:31-7.

17 Scheper MC, de Vries JE, de Vos R, et al. Generalized joint hypermobility in professional dancers: a sign of talent or vulnerability? Rheumatology 2013;52:651-8.

18 TÖNNIS D, HEINECKE A. Current Concepts Review - Acetabular and Femoral Anteversion. The Journal of Bone \& Joint Surgery 1999;81:1747-70.

19 Tönnis D, Heinecke A. Diminished femoral antetorsion syndrome: a cause of pain and osteoarthritis. J Pediatr Orthop 1991;11:419-31.

20 Clohisy JC, Carlisle JC, Beaulé PE, et al. A systematic approach to the plain radiographic evaluation of the young adult hip. J Bone Joint Surg Am 2008;90:47-66.

21 Carreira DS, Emmons BR. The reliability of commonly used radiographic parameters in the evaluation of the pre-arthritic hip. JBJS Rev 2019;7:e3-16.

22 Bedi A, Galano G, Walsh C, et al. Capsular management during hip arthroscopy: from femoroacetabular impingement to instability. Arthroscopy 2011;27:1720-31.

23 Benali Y, Katthagen BD. Hip subluxation as a complication of arthroscopic debridement. Arthroscopy 2009;25:405-7.

24 Ukwuani GC, Waterman BR, Nwachukwu BU, et al. Return to dance and predictors of outcome after hip arthroscopy for femoroacetabular impingement syndrome. Arthroscopy 2019;35:1101-8.

25 Canham CD, Yen Y-M, Giordano BD. Does femoroacetabular impingement cause hip instability? a systematic review. Arthroscopy: The Journal of Arthroscopic \& Related Surgery 2016;32:203-8.

26 Carter C, Wilkinson J. Persistent joint laxity and congenital dislocation of the hip. J Bone Joint Surg Br 1964;46-B:40-5.

27 Wynne-Davies R. Acetabular dysplasia and familial joint laxity: two etiological factors in congenital dislocation of the hip. review of 589 patients and their families. J Bone Joint Surg $\mathrm{Br}$ 1970;52:5487570:704-16.

28 Rodriguez M, Bolia IK, Philippon MD, et al. Hip screening of a professional ballet company using ultrasound-assisted physical examination diagnosing the at-risk hip. J Dance Med Sci 2019;23:51-7. 